\title{
Mind Conduct disorders in children with poor oral hygiene habits and attention deficit hyperactivity disorder in children with excessive tooth decay
}

Onur Burak Dursun ${ }^{1}$, Fatih Şengül2 ${ }^{2}$ İbrahim Selçuk Esin ${ }^{1}$, Tevfik Demirci² ${ }^{2}$ Nermin Yücel ${ }^{1}$, Mehmet Melih Ömezli

\author{
${ }^{1}$ Department of Child and Adolescent Psychiatry, Faculty of Medicine, University \\ of Ataturk, Erzurum, Turkey \\ ${ }^{2}$ Department of Paediatric Dentistry, Faculty of Dentistry, University of Atatürk, \\ Erzurum, Turkey \\ ${ }^{3}$ Department of Oral and Maxillofacial Surgery, Faculty of Dentistry, University \\ of Ordu, Ordu, Turkey
}

Submitted: 1 July 2014

Accepted: 5 August 2014

Arch Med Sci 2016; 12, 6: 1279-1285

DOI: 10.5114 /aoms.2016.59723

Copyright @ 2016 Termedia \& Banach

\section{Abstract}

Introduction: Dental caries and poor oral hygiene are among the major childhood public health problems. Although dental research frequently refers to the link between these conditions and behavioural issues, little attention has been paid to understanding the reason for oral health problems from a psychiatric point of view. The aim of this study was to examine the relationship between poor oral health and hygiene and parental attitudes towards child rearing, parents' and children's oral hygiene behaviours, and childhood psychiatric disorders.

Material and methods: This study included 323 children aged 3-15 years. Decayed, missing, filled and decayed, extracted, filled indices, the Simplified Oral Hygiene Index, the Strengths and Difficulties Questionnaire, and the Parent Attitude Research Instrument were used in the study.

Results: We found that the subjects' hyperactivity/inattention scores were positively correlated with poor oral health $(p=0.001)$ and heavy cariogenic food consumption $(p=0.040)$. Tooth brushing frequency was found to be significantly lower in children who have a risk for conduct/oppositional disorders than in their non-problematic peers $(p=0.001)$.

Conclusions: Dental health and oral hygiene behaviours have close links with psychiatric disorders and psychosocial issues. Improving cooperation between child psychiatrists and dentists seems to be important in the prevention of paediatric dental problems.

Key words: child psychiatry, dental health, conduct disorder, hyperactivity.

\section{Introduction}

Oral diseases, such as caries, periodontal disease, tooth loss, and oral mucosal lesions, are among the major childhood public health problems, due to their global burden and high prevalence [1]. The prevalence rates of dental caries only in children is $20-100 \%$, depending on the country [2]. In the United States, nearly $50 \%$ of children 5-9 years of age have at least one cavity or restoration, and this rate increases to $78 \%$ among 17-year-olds [2].

\author{
Corresponding author: \\ Onur Burak Dursun Assist. Prof. \\ Department of Child \\ and Adolescent Psychiatry \\ Faculty of Medicine \\ University of Ataturk \\ Erzurum, Turkey \\ Phone: +90 5066320584 \\ Fax: +90 4422361301 \\ E-mail: oburak.dursun@ \\ atauni.edu.tr
}


In recent decades, many research studies have reported that dental diseases are linked to social and behavioural factors [3, 4]. Improper oral hygiene, the widespread use of tobacco, and excessive consumption of sugar and alcohol are among the major risk factors of oral diseases [4]. Previous research studies have shown that these factors coexist with psychiatric disorders and are related to psychosocial determinants such as socioeconomic status and family environment $[5,6]$. However, despite this overlap between psychiatric disorders and dental problems, too little attention has been paid to understanding the reason for oral health problems from a psychiatric point of view. The psychiatric research on oral health to date has tended to focus on the oral health of specific groups, such as children with attention deficit hyperactivity disorder (ADHD) or autism or psychiatric inpatients [7-9].

The aim of this study was to examine the psychosocial correlates of oral health and oral hygiene, in particular by assessing whether poor oral health and hygiene are related to parental attitudes towards child rearing, parents' and children's oral hygiene behaviours, and childhood psychiatric disorders.

\section{Material and methods}

\section{Sampling}

This study was part of a research series examining the psychosocial aspects of different childhood dentistry problems. All of the studies were conducted in the city of Erzurum, Turkey. Ethical clearance was obtained from the ethics committee of Ataturk University. Children aged 3-15 who were admitted to the paediatric dentistry department of Ataturk University Faculty of Dentistry between 01/12/2012 and 01/05/2013 constituted the sample population of this study. All of the parents were informed about the study, and patients whose parents agreed to participate were included in the study. The parents whose children were accepted into the study provided written informed consent. Children with a known physical or psychiatric problem that might naturally affect oral health and/or oral hygiene behaviour, such as cleft lip and palate, mental retardation, and schizophrenia, were excluded. Children admitted by an adult other than their parents were also excluded due to ethical reasons. Because they are included in other ongoing studies, children with behaviour management problems in the dental clinic setting and children who were admitted due to a traumatic injury were not included in the study.

\section{Procedure}

All of the children were subjected to a dental examination by experienced paediatric dentists. The clinical examinations were performed in a dental chair in a dental care unit, using artificial light, a dental mirror, and a probe. To determine the oral health status of the subjects, we used the decayed, missing, filled teeth index and decayed, missing, filled surfaces index. The dentists used the Simplified Oral Hygiene Index (OHI-S) to assess the oral hygiene of the children. While their children were being examined, the parents were asked to complete a sociodemographic data form; the Strengths and Difficulties Questionnaire (SDQ), and the Parent Attitude Research Instrument (PARI).

\section{Instruments}

Decayed, missing, filled teeth index (DMFT/ $\mathrm{dmft}$ ) and Decayed, missing, filled surfaces index (DMFS/dmfs)

The dental examination form and rules followed the World Health Organization publication Oral Health Surveys: Basic Methods [10]. DMF is the total number of teeth or surfaces that are decayed (D), missing (M), or filled (F) in an individual. When the index refers to teeth, it is called the DMFT index; when it refers to tooth surfaces, it is called the DMFS index [10]. The DMFT and deft indices are used as dental caries indices to describe numerically the status and severity of dental caries in an individual. DMFT and DMFS refer to the permanent dentition. For the primary dentition, the deft and defs indices are used. For mixed dentition, the indices are called deft+DMFT and defs+DMFS. The higher the score, the greater is the number of affected teeth or surfaces [11].

\section{Simplified Oral Hygiene Index (OHI-S)}

The OHI-S, one of the most widely used oral hygiene measures, has been well established for evaluating dental plaque and dental calculus [12]. The OHI-S is composed of the Debris Index and the Calculus Index. Debris index scores range from 0 (No debris) to 3 (Soft debris covering more than two-thirds of the exposed tooth surface). Similarly, calculus index scores range from 0 (No calculus) to 3 (Supragingival calculus covering more than two-thirds of the exposed tooth surface or a continuous heavy band of subgingival calculus around the cervical portion of the tooth or both). The range of OHI-S scores is 0-6 [12].

\section{Strengths and Difficulties Questionnaire (SDQ)}

The hand-scored parent form of the SDQ, a brief, self-report, behavioural screening questionnaire about 3-16-year-olds, was used in this study [13]. The SDQ covers common areas of emotional and behavioural difficulties and asks about 
resultant distress and social impairment. The SDQ was translated into and validated in Turkish by Güvenir et al. [14]. The questionnaire consists of 25 items divided among five scales: emotional symptoms, conduct problems, hyperactivity/inattention, peer relationship problems, and pro-social behaviour. Each question has a three-point response scale (Not true $=0$; Somewhat true $=1$; Certainly true $=2$ ). The subscale score range is 0-10 and the total score range is 0-40; higher scores indicate more severe problems. We used the computerised SDQ scoring and report-writing program, which provides raw scores and interprets the results, according to clinical significance, as 'Unlikely to have a diagnosis', 'Slightly raised risk', or 'High risk' [15]. The algorithm makes separate predictions for three groups of disorders: conduct/ oppositional disorders, hyperactivity/inattention disorders, and anxiety/depressive disorders.

\section{Parent Attitude Research Instrument (PARI)}

The PARI is a 115-item (five subscales of 23 items each), four-point Likert scale developed to measure parental attitudes about child rearing in the context of family life [16]. This scale was adapted to Turkish in a shortened form consisting of five subscales of 60 items each. The Overparenting subscale reflects over-controlling, anxious, and over-demanding parental attitudes. The Democratic Attitudes subscale measures encouragement given to children and allowing them to express themselves in a supportive and sharing relationship. Attitude of Hostility and Rejection measures the mother's negative attitudes and feelings of incompetency. The Marital Discordance subscale measures the effect of marital discord on the child-rearing activities of the parents. The Authoritarian Attitude subscale measures over-punishing and rigid parental attitudes. Higher scores implied that the person agreed with the particular attitude being measured [17]. The PARI is frequently used to assess the parental attitudes of fathers as well as mothers in Turkey [18]. Therefore, items referring to "the denial of housewife roles" were excluded from the scales completed by fathers.

\section{Sociodemographic data form}

We used a sociodemographic data form prepared specifically for this study. Besides gathering classical sociodemographic data such as age, gender, socioeconomic status, and parent's education, the form also had questions regarding oral hygiene behaviours of the child and parents, such as frequency of tooth brushing, the time of the last tooth brushing, frequency of consuming junk food and smoking, and some habits (nail biting, finger sucking, and tongue biting) related to both psychiatry and dentistry.

\section{Statistical analysis}

The data were analysed using SPSS version 20.0 for Windows. The Mann-Whitney U-test was used to compare subjects with a high risk for psychiatric disorders and those without. To assess the correlation between the psychosocial factors and oral hygiene, we used Pearson's correlation analysis. $P$-values less than 0.05 were accepted as significant.

\section{Results}

A total of 323 children (162 males and $161 \mathrm{fe-}$ males) participated in the study. The subjects were placed into three groups according to their dentition stage: primary, mixed, or permanent dentition. The primary dentition group included 60 children (34 males and 26 females) with an age range of 3-6 years and a mean age of 5.3 \pm 0.9 years. The mixed dentition group included 212 children (103 males and 109 females) with an age range of 7-11 years and a mean age of $8.3 \pm 1.7$ years. The permanent dentition group consisted of 51 children $(24$ males and $27 \mathrm{fe}$ males) with an age range of 12-15 years and a mean age of $13.2 \pm 1.3$ years. Only one patient was receiving a psychotropic medication. Tooth brushing frequencies of family members were 1.8 times among fathers, 1.9 times among mothers and 1.7 times among children per day. The sociodemographic data of the participants are summarised in Table I.

\section{Psychosocial correlates of dental caries in children}

Child's age, mother's age, and father's education level were negatively correlated with the DMFT/deft scores of the children in the entire sample population. When we performed the analyses excluding the effect of age, and checked the same correlations within dentition subgroups, only father's education level was found to be correlated with DMFT/deft scores of children with mixed dentition $(p=0.007)$. Better oral hygiene was positively correlated with better oral health outcomes in all age groups. We also found that higher democratic parenting style scores, characterised by warmth and reasoning, correlated with higher mother's tooth brushing frequency and higher oral health (lower defs) scores of children with primary teeth $(p=0.026)$. Higher scores on mother's denial of housewife roles correlated with cariogenic food intake in children of all ages $(p=0.004)$ and oral health problems in children with permanent teeth (DMFT) $(p=0.033)$. 
Table I. Sociodemographic data of the participants

\begin{tabular}{|lcccc|}
\hline Parameter & $\begin{array}{c}\text { Primary dentition } \\
(<6 \text { years })\end{array}$ & $\begin{array}{c}\text { Mixed dentition } \\
(7-11 \text { years })\end{array}$ & $\begin{array}{c}\text { Permanent dentition } \\
(12-15 \text { years })\end{array}$ & $\begin{array}{c}\text { Overall } \\
\text { (3-15 years) }\end{array}$ \\
\hline Age & $5.3 \pm 0.9$ & $8.3 \pm 1.7$ & $13.2 \pm 1.3$ & $8.5 \pm 2.7$ \\
\hline Mother's age & $31.9 \pm 5.3$ & $34.7 \pm 6$ & $39.3 \pm 5.7$ & $34.8 \pm 6.7$ \\
\hline Father's age & $36.2 \pm 6.1$ & $39.7 \pm 6.1$ & $42.8 \pm 5.1$ & $39.5 \pm 6.2$ \\
\hline Number of children & $2 \pm 0.9$ & $2.7 \pm 1.3$ & $3.3 \pm 1.3$ & $2.6 \pm 1.3$ \\
\hline $\begin{array}{l}\text { Number of previous dental } \\
\text { visits of children }\end{array}$ & $3.2 \pm 3.2$ & $7.2 \pm 29.1$ & $5.4 \pm 8$ & $6.1 \pm 23.6$ \\
\hline $\begin{array}{l}\text { Children's tooth brushing } \\
\text { frequency per day }\end{array}$ & $1.8 \pm 0.7$ & $1.7 \pm 0.8$ & $1.9 \pm 1$ & $1.7 \pm 0.8$ \\
\hline $\begin{array}{l}\text { Mother's tooth brushing } \\
\text { frequency per day }\end{array}$ & $2.1 \pm 0.7$ & $1.9 \pm 0.8$ & $2.1 \pm 0.9$ & $1.9 \pm 0.8$ \\
\hline $\begin{array}{l}\text { Father's tooth brushing } \\
\text { frequency per day }\end{array}$ & $1.8 \pm 0.7$ & $1.8 \pm 0.8$ & $1.9 \pm 1$ & $1.8 \pm 0.8$ \\
\hline Male, $n$ (\%) & $34(56.7)$ & $103(48.6)$ & $24(47.1)$ & $162(50.2)$ \\
\hline Female, $n$ (\%) & $26(43.3)$ & $109(51.4)$ & $27(52.9)$ & $161(49.8)$ \\
\hline
\end{tabular}

\section{Psychosocial correlates of oral hygiene in children}

We found that oral hygiene was negatively correlated with child's age and number of previous dental visits. Boys had significantly worse oral hygiene scores than girls $(p=0.013)$. Finger sucking behaviours were also negatively correlated with oral hygiene, and positively correlated with behavioural problems $(p=0.033)$ and total SDQ scores $(p=0.010)$. Although not reflected in the children, we also found that a longer period of time between the current examination and the last tooth brushing on the part of both parents correlated with marital discord. Table II summarises the psychosocial correlates of oral hygiene.

\section{Relationship between psychiatric disorders and oral health/hygiene}

We used two statistical assessment methods to identify the relationship between SDQ scores and oral health. First, we assessed the psychosocial and oral health correlations of the SDQ raw scores. Then, we compared the children who were deemed to have a risk of psychiatric disorders and the children whose scores were in the normal range for that particular SDQ domain.

The analysis of raw scores revealed that hyperactivity/inattention scores were positively correlated with poor oral health $(p=0.033)$ and heavier cariogenic food consumption $(p=0.040)$ in all age groups. Child's tooth brushing frequency was positively correlated with kind and helpful behaviours $(p=0.009)$ and negatively correlated with conduct problems $(p=0.002)$.

The comparison between the children unlikely to have a diagnosis and the children at risk of psychiatric disorders revealed that the oral health of children with primary dentition (aged 3-6) at risk of ADHD was significantly worse than the oral health of their peers with normal ADHD scores. Tooth brushing frequency (of children

Table II. Correlation analysis of the Oral Hygiene Index and psychosocial factors

\begin{tabular}{|lcccccccc|}
\hline Parameter & \multicolumn{2}{c}{$\begin{array}{c}\text { Primary dentition } \\
\text { < 6 years }\end{array}$} & \multicolumn{2}{c}{$\begin{array}{c}\text { Mixed dentition } \\
\text { 7-11 years }\end{array}$} & $\begin{array}{c}\text { Permanent dentition } \\
12-15\end{array}$ years & \multicolumn{2}{c|}{$\begin{array}{c}\text { All dentitions } \\
\text { 3-15 years }\end{array}$} \\
\cline { 2 - 9 } & $r(\mathbf{s})$ & $P$-value & $r(\mathbf{s})$ & $P$-value & $r(s)$ & $P$-value & $r(s)$ & $P$-value \\
\hline Age & 0.106 & 0.436 & -0.017 & 0.815 & -0.062 & 0.676 & -0.144 & $0.013^{*}$ \\
\hline Gender & -0.196 & 0.148 & -0.078 & 0.278 & -0.240 & 0.101 & -0.143 & $0.013^{*}$ \\
\hline Finger sucking & -0.141 & 0.299 & -0.169 & $0.019^{*}$ & -0.040 & 0.788 & -0.117 & $0.044^{*}$ \\
\hline $\begin{array}{l}\text { Cariogenic food } \\
\text { consumption }\end{array}$ & 0.236 & 0.086 & -0.007 & 0.925 & 0.303 & $0.038^{*}$ & 0.098 & 0.100 \\
\hline $\begin{array}{l}\text { Number of } \\
\text { previous dental } \\
\text { visits of children }\end{array}$ & 0.026 & 0.866 & -0.147 & 0.081 & -0.074 & 0.669 & -0.136 & $0.043^{*}$ \\
\hline
\end{tabular}

Analysed by Pearson's correlation. ${ }^{*}$ Correlation is significant at the 0.05 level; ${ }^{* *}$ Correlation is significant at the 0.01 level. 
$(p=0.001)$ and their mothers $(p=0.023)$ and fathers $(p=0.018))$ was significantly lower in children at risk of conduct/oppositional disorders than that of their peers without a significant problem in this area. ADHD risk and conduct/oppositional disorder risk were more prevalent in boys. There was no significant difference between children with a risk for emotional disorders and children without that risk.

\section{Discussion}

The sociodemographic factors that were found to be correlated with overall oral health scores in this study were consistent with the findings reported in previous studies. Good oral hygiene is one of the best known protectors of oral health [19]. It is also well known that the rate of progression of tooth decay slows down with increased age [20]. Low father's education level and young age in mothers have been shown to be risk factors for childhood caries in different cultures [21, 22].

This study provides two important findings to consider regarding the relationship between psychopathology and oral health. The first finding is the correlation between hyperactivity/inattention problems and poor oral health in children. Although this correlation was true for all age groups, there was a stronger correlation in younger children, for whom the correlation was confirmed by two different statistical measures. Only a few studies have examined the oral health status of children with ADHD. Despite some controversial results, most of these studies have claimed that ADHD is a risk factor for dental caries [23]. For example, in a large cohort of German children, Kohlboeck found a relationship between abnormal rates of hyperactivity/inattention symptoms and non-cavitated caries lesions [24]. Similarly, Broadbent reported that children with ADHD were nearly 12 times as likely to have a high DMFT score than children who did not have ADHD [25]. The results of the current study corroborate these earlier findings, suggesting a relationship between dental caries and ADHD.

The reason for poor oral health in children with ADHD is another research question; there are two main explanations. One explanation is that children with ADHD exhibit poorer oral health behaviours, such as less tooth brushing, than children without ADHD, and the second is that children with ADHD tend to consume greater amounts of cariogenic food [23]. Our results, which showed that children with ADHD consume more cariogenic food than their peers, were consistent with previous research, suggesting that improper dietary habits might be a reason for poor oral health in children with ADHD. The developmental course of ADHD might explain why the correlation was only confirmed in younger children. Studies have shown that hyperactive-impulsive behaviour patterns appear early, particularly during the preschool years, and decline during the developmental process, while inattention problems increase with age [26]. The higher levels of impulsivity exhibited by younger children might result in a lack of control regarding cariogenic food consumption, thus causing more oral health problems compared to older children.

The second finding to consider is the lower frequency of tooth brushing observed in children with a risk of conduct/oppositional disorders and their parents. Moreover, the oral hygiene habits of the children in the study were positively correlated with pro-social behaviours and negatively correlated with conduct problems. These results can be understood through Gray's biopsychological theory of personality. Gray hypothesised that three systems - the behavioural inhibition system (BIS), the behavioural activation system (BAS), and the fight/flight system (FFS) - control behaviours. The BIS is activated by unfavourable stimuli such as negative events, and it responds to these cues by avoiding such negative and unpleasant situations. In contrast, the BAS is the system that is aroused when rewarding cues are received, and it leads individuals to achieve their goals [27]. The BAS is clearly dominant over the BIS in children with behavioural problems compared with their peers who have better pro-social skills [28]. Therefore, these children resist performing a desired and rewarded behaviour. Health-related behaviours are not excluded from this construct, and the poorer oral hygiene behaviours of children with CD/ODD symptoms may be related to defects in their behavioural control system.

The relationship between parenting attitudes and oral health is also important. In this study, there was a positive correlation between democratic parenting and mother's oral hygiene behaviour and young children's oral health. It is clear that mothers who primarily use democratic parenting attitudes are good models for their children in many behavioural domains, including health-related behaviours $[29,30]$. However, there are controversial findings in the literature regarding the correlation between parenting style and oral health. Although some studies did not identify a relationship [31], other studies reported that a parenting style based on sharing and responsiveness had a positive effect on the oral health of children [32]. For example, Brukiene stated that an oral health education programme based on enhancing parents' attitudes towards supportiveness and responsiveness was more effective than the conventional oral health education programmes [32]. The reason democratic parenting did not affect the older age group is unclear, but 
it may be due to the nature of adolescence, when parental influence loses its effect [33].

We also found that cariogenic food consumption and the oral health problems of children with permanent dentition increased in correlation with mothers' denial of housewife roles. The control a mother exhibits in encouraging or limiting what a child eats is an important factor that influences children's eating habits [34]. In the case of a mother's 'denial of roles', this control is diminished. In addition, feeding children is considered one of the major roles of a housewife in many cultures [35]. If a mother denies this role, the amount of home cooking decreases and children tend to eat junk food, which may result in poor oral health.

The topic of oral habits is a common area of interest for child psychiatrists and dentists. Despite the decline in developed countries in recent years, finger sucking is still a common oral habit in childhood [36]. Although numerous theories have been proposed to explain finger sucking behaviour, psychoanalytic theory has a direct reference to this behaviour. In psychoanalytic theory, finger sucking is considered a method of obtaining oral satisfaction, which refers to the unmet needs in the infant-mother relationship and serves to relieve stress [37]. Many studies have shown a relationship between this behaviour and psychiatric disorders, but the behaviour is not necessarily a symptom of psychopathology [38]. The findings of this study support the previous research, indicating that there may be a relationship between psychopathology and finger sucking. To our knowledge, there have not been any studies examining the relationship between finger sucking and oral hygiene with which to compare our results. Our results, which indicate a negative correlation between oral hygiene and finger sucking, may be explained in physical and psychological contexts. In a physical context, prolonged sucking habits in children may result in anterior open bite and lead to oral health problems $[39,40]$. From a psychological point of view, finger sucking might be a manifestation of behavioural problems, which may lead to poor health-related behaviours, including oral hygiene [41].

In conclusion, dental health and oral hygiene behaviours have close links with psychiatric disorders and psychosocial issues. The current study has contributed to the existing research by showing this link and pointing out some important psychiatric issues that might be considered in dentists' daily practice with children. The relationship between ADHD and poor oral health and the relationship between conduct/oppositional disorder and poor oral hygiene suggest that dentists should consider psychiatric problems in children with significant dental problems. Our findings, which show a positive correlation between oral hygiene and positive behaviours and a negative correlation between oral hygiene and negative behaviours, can be important for prevention studies. The findings can be interpreted to mean that prevention studies aiming to enhance oral hygiene behaviours should be planned as general behavioural enhancement programmes rather than as programmes targeting only oral hygiene behaviours. This study has also contributed to enhancing our understanding of the effect of family environment and parenting style on the oral health of children. Finally, improving cooperation between child psychiatrists and dentists seems to be important for the prevention of paediatric dental problems and the early detection of psychiatric problems.

The generalisability of these results is subject to certain limitations. Although we used objective measures to assess oral hygiene and oral health, it was not possible for us to examine the oral health behaviours objectively; therefore, these data are based on self-reporting, and thus are quite subjective. The sample size of this study is acceptable with regards to similar previous research, but it is still insufficient for generalising the results. Another limitation is about the instruments used in the study. Instead of using screening questionnaires (SDQ) and examining the correlations of children with high risk for disorders, it would be better to use structured interviews and study the correlations of particular diagnoses. This was particularly difficult for us because of the high costs and time-consuming nature of these tools.

\section{Conflict of interest}

The authors declare no conflict of interest.

\section{References}

1. Petersen PE. World Health Organization global policy for improvement of oral health - World Health Assembly 2007. Int Dent J 2008; 58: 115-21.

2. Bagramian RA, Garcia-Godoy F, Volpe AR. The global increase in dental caries. A pending public health crisis. Am J Dent 2009; 22: 3-8.

3. Chen MS, Hunter P. Oral health and quality of life in New Zealand: a social perspective. Soc Sci Med 1996; 43: 1213-22.

4. Petersen PE, Bourgeois D, Ogawa H, Estupinan-Day S, Ndiaye C. The global burden of oral diseases and risks to oral health. Bull World Health Organ 2005; 83: 661-9.

5. Chandra P, Anandakrishna L, Ray P. Caries experience and oral hygiene status of children suffering from attention deficit hyperactivity disorder. J Clin Ped Dent 2009; 34: 25-9.

6. Prinz RJ, Roberts WA, Hantman E. Dietary correlates of hyperactive behavior in children. J Consult Clin Psychol 1980; 48: 760-9.

7. Kumar M, Chandu G, Shafiulla M. Oral health status and treatment needs in institutionalized psychiatric patients: one year descriptive cross sectional study. Ind J Dent Res 2006; 17: 171-7. 
8. Holmberg K, Fernell E, Ek U, Dahllöf G. Oral health, dental anxiety, and behavior management problems in children with attention deficit hyperactivity disorder. Eur J Oral Sci 2006; 114: 385-90.

9. Shapira J, Mann J, Tamari I, et al. Oral health status and dental needs of an autistic population of children and young adults. Spe Care Dentist 1989; 9: 38-41.

10. World Health Organization. Oral health surveys: basic methods. World Health Organization 1987.

11. Assaf AV, Meneghim MC, Zanin L, Mialhe FL, Pereira AC, Ambrosano GM. Assessment of different methods for diagnosing dental caries in epidemiological surveys. Comm Dent Oral Epid 2004; 32: 418-25.

12. Greene JC. The Oral Hygiene Index: development and uses. J Periodontol 1967; 38: 625-37.

13. Goodman R. The extended version of the Strengths and Difficulties Questionnaire as a guide to child psychiatric caseness and consequent burden. J Child Psychol Psychiatry 1999; 40: 791-9.

14. Güvenir T, Özbek A, Baykara B, Arkar H, Şentürk B, Incekaş S. Psychometric properties of the Turkish version of the Strengths and Difficulties Questionnaire (SDQ). Turk J Child Adol Mental Health 2008; 15: 65-74.

15. www.sdq.info

16. Schaefer ES, Bell RQ. Development of a parental attitude research instrument. Child Dev 1958; 29: 339-61.

17. Le Compte WA, Oner N. Development of the Turkish edition of the State-trait anxiety inventory. Cross-cult Anxiety 1976; 1: 51-67.

18. Alyanak B, Kilinçaslan A, Harmanci HS, Demirkaya SK, Yurtbay T, Vehid HE. Parental adjustment, parenting attitudes and emotional and behavioral problems in children with selective mutism. J Anxiety Disord 2013; 27: 9-15.

19. Petersen PE. Sociobehavioural risk factors in dental caries-international perspectives. Comm Dent Oral Epid 2005; 33: 274-9.

20. Selwitz RH, Ismail Al, Pitts NB. Dental caries. Lancet 2007; 369: 51-9.

21. Khan MN, Cleaton-Jones PE. Dental caries in African preschool children: social factors as disease markers. J Pub Health Dent 1998; 58: 7-11.

22. Petersen PE. Oral health behavior of 6-year-old Danish children. Acta Odontol 1992; 50: 57-64.

23. Blomqvist M, Holmberg K, Fernell E, Ek U, Dahllöf G. Dental caries and oral health behavior in children with attention deficit hyperactivity disorder. Euro J Oral Sci 2007; 115: 186-91.

24. Kohlboeck G, Heitmueller D, Neumann C, et al. Is there a relationship between hyperactivity/inattention symptoms and poor oral health? Results from the GINIplus and LISAplus study. Clin Oral Investig 2013; 17: 1329-38.

25. Broadbent JM, Ayers KMS, Thomson WM. Is attention-deficit hyperactivity disorder a risk factor for dental caries? Caries Res 2004; 38: 29-33.

26. Berger I, Nevo Y. Early developmental cues for diagnosis of attention deficit/hyperactivity disorder in young children. Dev Disabil Res Rev 2011; 17: 170-9.

27. Gray JA. Framework for a taxonomy of psychiatric disorder. In: Emotions: essays on emotion theory. van Goozen SHM, van de Poll N, Sergeang JA, et al. (eds.) Psychology Press 1994; 29-59.

28. Matthys W, Goozen SH, Vries HD, Cohen-Kettenis PT, Engeland HV. The dominance of behavioural activation over behavioural inhibition in conduct disordered boys with or without attention deficit hyperactivity disorder. J Child Psychol Psychiatry 1998; 39: 643-51.

29. Santrock J. A topical approach to life-span development. $2^{\text {nd }}$ ed. McGraw-Hill, New York 2004; 200-25.

30. Park H, Walton-Moss B. Parenting style, parenting stress, and children's health-related behaviors. J Dev Behav Ped 2012; 33: 495-503.

31. Ng S, Demopoulos C, Mobley C, Ditmyer M. Parenting style and oral health status. Open J Pediatr 2013; 3: 188-94.

32. Brukienè V, Aleksejūnienè J. Is the authoritative parenting model effective in changing oral hygiene behavior in adolescents? Health Edu Res 2012; 27: 1081-90.

33. Steinberg L. We know some things: parent-adolescent relationships in retrospect and prospect. J Res Adol 2001; 11: 1-19.

34. Birch LL, Fisher JO. Development of eating behaviors among children and adolescents. Pediatrics 1998; 101 : 539-49.

35. Daniels S, Glorieux I, Minnen J, van Tienoven TP. More than preparing a meal? Concerning the meanings of home cooking. Appetite 2012; 58: 1050-6.

36. Davidson L. Thumb and finger sucking. Pediatr Rev 2008; 29: 207-8.

37. Blenner S. Thumb sucking. In: Developmental and behavioral pediatrics. A handbook for primary care. Parker SJ, Zuckerman BS, Augustyn M (eds.). $2^{\text {nd }}$ ed. Lippincott Williams and Wilkins, Philadelphia 2005; 348.

38. Conelea CA, Tucker BT, Woods DW. Tic and habit disorders. In: Handbook of clinical psychology competencies. Thomas JC, Hersen M (eds.). Springer Science Business Media, New York 2010; 1403-28.

39. Creighton PR. Common pediatric dental problems. Pediatr Clin North Am 1998; 45: 1579-600.

40. Curzon M. Dental implications of thumb-sucking. Pediatrics 1974; 54: 196-200.

41. Mahalski PA, Stanton WR. The relationship between digit sucking and behaviour problems: a longitudinal study over 10 years. J Child Psychol Psychiatry 1992; 33: 913-23. 